\title{
The Influence of Racial Factors on Psychiatric Diagnosis: A Review and Suggestions for Research
}

\author{
Harold W. Neighbors, Ph.D. \\ James S. Jackson, Ph.D. \\ Linn Campbell, M.D. \\ Donald Williams, M.D.
}

\begin{abstract}
Research on race and diagnosis initially focused on black-white differences in depression and schizophrenia. Statistics showing a higher treated prevalence of schizophrenia and a lower prevalence of depression for blacks seemed to support the claim that blacks did not suffer from depression. Others argued, however, that clinicians were misdiagnosing depression in blacks. This article reviews empirical studies of racial differences in individual symptoms and summarizes the evidence on misdiagnosis. It argues that more attention must be paid to resolving two contradictory assumptions made by researchers working in the area of race and diagnostic inference: (1) blacks and whites exhibit symptomatology similarly but diagnosticians mistakenly assume that they are different; (2) blacks and whites display psychopathology in different ways but diagnosticians are unaware of or insensitive to such cultural differences. The article concludes with suggested research directions and a discussion of critical research issues.
\end{abstract}

\section{INTRODUCTION}

Psychiatric epidemiology has been oriented toward research on discrete psychiatric disorders since the early 1980's (Regier, 1982). Unfor-

Address all correspondence to: Harold W. Neighbors, Ph.D., University of Michigan School of Public Health, Department of Health Behavior and Health Education, $1420 \mathrm{~W}$ ashington Heights, Ann Arbor, Michigan 48109-2029. The authors would like to thank Dr. Clifford Broman (Michigan State University Department of Sociology), Dr. Neal Ryan (University of Pittsburgh Western Psychiatric Institute), Dr. Phillip Margolis (University of Michigan Medical Center Department of Psychiatry) and two anonymous reviewers for helpful comments on earlier drafts of this manuscript. Special thanks Ms. Johanna Lackner for editorial suggestions and helping to prepare the final version for publication. 
tunately, many psychiatric epidemiologists have chosen to apply diagnostic instruments developed in white samples to blacks, assuming that these instruments measure the same construct in both groups (Vernon \& Roberts, 1981; Good \& Good, 1986). Even though it is commonly accepted that the expression of psychological distress can vary across different cultural groups, this factor has not been taken into account when compiling the pathognomic indicators used in epidemiologic community surveys (Dohrenwend \& Dohrenwend, 1974, pp. 432-433).

Current procedures in psychiatric epidemiologic classification assume that the clinical diagnostic process can be directly translated to the epidemiologic community survey (Weissman \& Klerman, 1978). Interest among psychiatric epidemiologists in the true prevalence of specific mental disorders raises a number of important questions about how racial factors influence the process of diagnostic inference (Loring \& Powell, 1988; Roberts, 1987).

Numerous studies have attempted to investigate the process of diagnostic classification in black patients (Raskin, Crook \& Herman, 1975; Tonks, Paykel \& Klerman, 1970; Helzer, 1975; Simon et al, 1973; Tonks et al., 1970; Hanson \& Klerman, 1974; DeHoyos \& DeHoyos, 1965; Vitols et al., 1963; Liss, Welner, Robins \& Richardson, 1973; Welner, Liss \& Robins, 1973: Mukherjee et al., 1983). Prange and Vitols (1962) early on raised the issue of race differences in mental disorder from a diagnostic perspective, noting that while rare, depression did occur in blacks. Other writers (Bell \& Mehta, 1980, 1981; Jones et al., 1981, 1982) have taken the opposite stance, designing studies to show not only that depression exists in blacks, but that it is quite prevalent and often misdiagnosed (Jones \& Gray, 1986).

In general, these studies are distributed over a wide time period, a host of methodologies, treatment agencies and disorders. The findings suggest that much ambiguity remains in what is known about race differences in presenting symptomatology. Some studies support the proposition that blacks and whites differ in the presentation of clinical symptoms while others conclude just the opposite. In our opinion, these contradictory findings are due to the lack of systematic research programs on the issue of race differences in presenting complaints. Thus, this paper has two objectives. First, the literature on race differences in diagnostic inference is reviewed. Second, important issues for research on race and diagnosis are discussed.

\section{Evidence of Misdiagnosis}

After providing evidence that blacks do have depression, most writers have relied on the misdiagnosis hypothesis to explain the previously 
noted relationship between race and the diagnosis of schizophrenia (higher treated prevalence among blacks) and depression (lower treated prevalence among blacks). Bell and Mehta (1980), for example, attempted to focus more attention on misdiagnosis by presenting three case histories of blacks diagnosed as chronic undifferentiated schizophrenics, yet showing considerable manic phenomenology.

Although the studies cited above focused primarily on black-white comparisons of individual symptoms, a number uncovered evidence consistent with the hypothesis that blacks are being routinely misdiagnosed. As a case in point, despite the fact that a high level of depressive symptomatology was a requirement for participation in their study, Raskin et al. (1975) found that whites were more likely to receive a diagnosis of depression while blacks were more likely to be diagnosed schizophrenic.

Simon et al. (1973) found that $15 \%$ of whites but none of the blacks were diagnosed as having affective illness, despite the fact that there were no race differences in psychopathology as measured by the research project's symptom scales. Furthermore, there were no race differences in the project's diagnosis (which used a more structured interviewing technique) even though the hospital charts reported substantial black-white differences in depression and schizophrenia. An analysis by Liss et al. (1973) found no race differences in diagnosis, but there was a stronger degree of association between symptoms and diagnosis for whites than blacks. Welner et al. (1973) followed up 92 patients who were given a computer-generated diagnosis. The results showed a higher rate of disagreement between the computer-generated diagnosis and the diagnosis based on clinical impression for blacks than whites.

Mukherjee et al. (1983) reviewed the records of 76 ( 37 white, 21 black, 18 Hispanic) patients, diagnosed as bipolar according to DSM-III criteria. Fifty-two (68\%) had received a previous diagnosis of schizophrenia. A multiple regression analysis revealed that blacks were more likely to have been previously so diagnosed, even after the effects of other variables were taken into account. Similarly, blacks were more likely to have been diagnosed as paranoid schizophrenic, which the authors noted was difficult to explain given that there were no black-white differences in persecutory delusions, ideas of reference, anger or violent behavior. Mukherjee et al. (1983) noted that while blacks may be admitted to hospitals in a more severe (psychotic) state, their findings probably reflected a lower threshold of psychiatric evaluation of such symptoms in blacks, due to an assumption of schizophrenia.

This review suggests that skin color influences the process of diagnostic classification. A number of the studies reviewed found significant 
differences in the diagnosis of blacks when comparing structured, controlled clinical decision-making to an unstructured clinical interview (Vitols et al., 1963; Welner et al., 1973; Simon et al., 1973; Liss et al., 1973). While it cannot be concluded that structured instruments should be viewed as the ultimate criterion of validity, an unstructured interviewing procedure is more prone to influence by unsubstantiated clinical impressions (such as, "blacks do not get depressed", or that "hallucinations and delusions occur only in schizophrenia") than a more structured approach. If nothing else, such findings point to the structured interview as an important research tool for studying black-white differences in the diagnostic process (Welner et al., 1973, p. 487).

\section{A Fundamental Contradiction}

Assessing the degree to which diagnostic norms developed on whites are also appropriate for blacks will involve a research strategy of racial comparison. The clinical expression of psychiatric morbidity of one group must be evaluated within the context of the other. Such a research program must address two fundamental assumptions which are routinely made by researchers working in the diagnostic inference area. The first is that blacks and whites are very similar but diagnosticians assume that they are different. That is, both racial groups exhibit their symptomatology in essentially the same manner. As a result, the diagnostic nomenclature and criteria for discriminating one disorder from another are equally applicable to blacks and whites. Diagnostic errors (if they occur) are the result of stereotypes that clinicians have about black people (Thomas \& Sillen, 1972).

The second assumption is that blacks and whites display psychopathology in different ways but diagnosticians incorrectly assume they are the same. Here, diagnostic errors result from the fact that clinicians are unaware of, or insensitive to, cultural differences in the way that the same disorder can be displayed in different racial groups. Bipolar affective disorder and schizophrenia are classic examples. Circumstantial evidence suggests that blacks with bipolar disorder are more likely to have symptoms of hallucinations and delusions which clinicians assume are indicative of schizophrenia. As a result, blacks who actually have affective disorders are incorrectly diagnosed as schizophrenic.

On first glance, it would appear that these two assumptions are mutually exclusive and contradictory because they imply that blacks and whites can be both alike and different at the same time. It is more likely, however, that these contradictory perspectives are actually re- 
flective of the lack of systematic research on this topic. Previous research on race differences has shown that the degree to which blacks and whites are the same or different usually depends upon other factors. For years it was thought that the level of distress was the same for blacks and whites, once socioeconomic differences were taken into account (Warheit et al., 1975). Recently, however, it has been shown that the prevalence of distress among low-income blacks is distinctly different from the prevalence among low-income whites; but among the upper classes, blacks and whites display essentially similar rates of psychological distress (Kessler \& Neighbors, 1986). It is possible that empirical research would reveal similar patterns in the diagnostic area. Conceivably, the degree to which blacks and whites differ in the presentation of psychopathological symptoms is conditional upon social class, gender, the specific disorder or some other third variable.

The apparent dilemma of the similarities and differences between blacks and whites in how they display psychological distress is a more specific example of the kind of classification problem psychiatric epidemiology has been grappling with for years. The argument centers around trying to find an appropriate data collection process and valid criteria with which to make judgments about who is "right" and who is "wrong."

One approach to resolving this dilemma is to take a strong a priori position. In fact, much of the discussion has been influenced by the stance of researchers who take the uniqueness of black Americans as a given (Akbar, 1980). On the other hand, a more integrationist position would argue just the opposite-that blacks and whites in the United States, are more similar than different. It is a small step to move from this latter assumption to apply any and all instruments indiscriminantly to both groups. In fact, this is precisely the perspective taken by the majority of epidemiologists and clinicians who choose to ignore the investigation of possible race differences in the expression of psychopathology. Both of these positions are equally non-satisfying solutions to the problem. What is needed is a systematic, developmental research program that empirically addresses the difference/similarity contradiction.

It is also apparent that if we do not resolve this dilemma, our thinking on these matters will remain confused and the results of our research uninterpretable. There are undoubtedly problems in basing our knowledge about race differences in mental disorder upon data which rely solely upon such structured instruments as the Diagnostic Interview Schedule. The diagnostic criteria upon which the DIS operates (DSMIII-R), were compiled by clinicians working with predominantly white 
patient populations. Thus, one could argue that we are merely replacing one biased system with another.

Despite such criticisms, the use of structured instruments in conjunction with explicit diagnostic criteria should be viewed as improvements over previous techniques for a number of reasons. First, structured instruments ensure that data collection is comprehensive and uniform across all interviewers. It has been shown, for example, that clinicians often fail to cover all diagnostic categories before arriving at a final assessment (Helzer, J., Robins, L., McEvoy, L. et al., 1985). Second, there is evidence that many "front-line" clinicians do not adhere to the strict decision-making criteria of DSM-III-R (Craig, Goodman, \& Haugland, 1982). Many continue to employ their own idiosyncratic procedures and criteria, which makes it difficult to isolate the factors which might explain differential outcomes by race. A computer diagnostic program used to analyze data collected by structured instruments, on the other hand, does not vary from the inclusion-exclusion criteria specified by the DSM-III. Third, because the decision-making rules are so explicit, procedures can be replicated, a minimum methodological requirement for comparative diagnostic studies.

In summary, this body of research suffers from the classic problem of not having a "gold standard" against which to judge diagnostic decisionmaking. At this stage of the research enterprise, reliance upon the highly structured format of an instrument like the Diagnostic Interview Schedule in conjunction with the explicit criteria of the DSM-III-R makes such research potentially superior to previous work precisely because it employs procedures which are replicable and reliable; we cannot hope to tackle the validity issue without an acceptable level of reliability (Weissman \& Klerman, 1978).

\section{RESEARCH RECOMMENDATIONS}

The procedures to be used for addressing issues of validity within this context should be no different from those employed for any comprehensive research program. The exception is that closer attention must be paid to hypotheses about race. Feighner and Herbstein (1987) have outlined a six-stage model of research focused on diagnostic validity. While it is beyond the scope of the present paper to provide a detailed description of such a research initiative, they argue that the place to begin is with a careful description of the physical and psychological symptoms that make up different syndromes according to racial group, 
including the delineation of psychosocial factors. Such descriptive phenomenological research should result in the compilation of symptom indicators for various disorders and form the basic building blocks with which to compare blacks and whites in a more rigorous, systematic manner.

To adequately test the hypothesis of race differences in the presentation of individual psychopathological symptoms, one should have diagnostically homogeneous samples of black and white patients. Mixing two or more diagnostic entities would result in ambiguous interpretations of the findings, since different diagnostic categories could evidence different frequencies in key symptoms. Currently, the best manner in which to arrive at such "pure" groups is through the use of a structured instrument and strict adherence to operationally explicit diagnostic criteria. Symptom checklists could then be used to record the presence or absence of single indicators of psychopathology.

Given the new diagnostic technology that has become available since the early 1980's, and the use of specific diagnostic criteria, there are methodological improvements that can be made in the research designs employed in prior studies. For example, few of the studies previously reviewed used any type of structured research instrument and those that did are now out-dated (Simon et al., 1973; Tonks et al., 1970). Practically all of the studies (see Jones et al., 1981; Lipton \& Simon, 1985 and Mukherjee et al., 1983 for exceptions) were pre-DSM-III and did not use the hierarchical system for ruling out affective disorder before making a diagnosis of schizophrenia. Only one of the investigations reviewed employed the Schedule for Affective Disorders and Schizophrenia (Mukherjee et al., 1983) and none used the Present State Exam, Psychiatric Epidemiology Research Interview nor Structured Clinical Interview for DSM-III-R. This is particularly surprising given that much of the criticism on race and diagnosis is directed against the use of unstructured clinical interviewing procedures (Adebimpe, 1981; Simon et al., 1973; Tonks et al., 1970; Mukherjee et al., 1983).

Mentioning structured interviews raises questions about the use of the Diagnostic Interview Schedule (DIS) with blacks. So far, only one study has examined the operation of the DIS with black patients. Hendricks et al. (1983) administered the Diagnostic Interview Schedule in a sample of adult black patients (12 depressed, 11 schizophrenic and 23 alcoholic) for alcoholism, depression and schizophrenia. Patients were also diagnosed by clinicians using DSM-III criteria. Diagnostic concordance between the DIS diagnosis and the chart diagnosis was calculated for depression, schizophrenia and alcoholism. Concordance 
was perfect for depression, .50 for alcoholism and only .24 for schizophrenia (Hendricks et al., 1983, p. 669). Although the methodology used in the Hendricks et al. (1983) study is limited, it does provide one possible direct assessment of diagnoses provided by clinicians under usual clinical interviewing procedures. Hendricks et al. (1983) employed the DIS with black patients only. It would be more appropriate, however, to study race differences, comparing DIS and chart diagnostic agreement for blacks and whites. Here, interest would lie in the relative diagnostic concordance in both groups. A finding of lower concordance for blacks than whites would raise the possibility of problems in the diagnosis of black patients. Such research is needed in order to provide meaningful interpretations of race-difference findings from the Epidemiologic Catchment Area Program (see Williams, 1986, pp. 47-48).

The logical next step would be to employ these structured and unstructured methods to assess whether white and black clinicians differentially diagnose black and white clients. This would provide an opportunity to test the hypothesis that black clinicians will make fewer errors in diagnosing black clients than white clinicians because of less social and cultural distance (Casas, 1986; Good \& Good, 1986; Ruiz, 1983; Mukherjee et al., 1983; Hanson \& Klerman, 1974).

\section{CONCLUSIONS}

This review has shown that the evidence on race differences in individual indicators of psychopathology is equivocal and contradictory. Some studies find no (or very small) race differences among black and white depressed and schizophrenic patients while other studies do find differences. When differences are found, they are usually among those symptoms that Jones and Gray (1986), Adebimpe (1981) and Bell and Mehta $(1980,1981)$ have argued increase the likelihood of misdiagnosishallucination and delusions (Liss et al., 1973). Other studies have found that religious delusions and paranoid delusions more often occur in blacks (Gynther et al., 1971; Singer, 1977; Figelman, 1968; Sletten et al., 1972; Steinberg et al., 1977).

While this review has emphasized issues pertaining to diagnostic and statistical categories, researchers should not limit the purview of their research to these issues alone. We should appreciate the fact that treatment decisions are made on the basis of multiple factors and are not always diagnostic specific. Therefore, in the future, researchers 
must also consider mounting investigations of how racial factors affect clinical decision making in the use of antipsychotic and antidepressant medication, combining medication and psychotherapy, and the use of various types of psychotherapy, e.g., brief or long-term, suggestive or educative, nondirective or insight-oriented (Jones, 1985). Such decisions are influenced by the availability of services and the particular theoretical and therapeutic bias of the deciding clinician. However, they should also include the evaluation of the patient's capacities to benefit from specific treatment approaches. This research direction should include studies of how these factors are evaluated, including whether there are cultural differences in the manner that treatment decisions are made and their outcomes (Perry, 1987; Frances et al., 1987).

Despite the need to address these important treatment issues, however, we feel that for epidemiologic and risk factor research, the most useful place to begin is in the diagnostic inference area. Assessing the relative mental health status of blacks and whites is a long-standing scientific question which has never been satisfactorily answered due to a host of methodological problems (Fischer, 1969; Kramer et al., 1973). In addition to the interesting scientific issue, however, is the important practical aspect of providing an adequate epidemiologic research basis for developing mental disorder prevention programs (Neighbors, 1987). It is our hope that the issues discussed here will motivate researchers to further investigate how racial factors influence diagnostic inference. The eventual accumulation of knowledge in this area should result in the improvement of epidemiologic and prevention research as well as clinical treatment.

\section{REFERENCES}

Abedimpe, V.R. (1981). Overview: White norms and psychiatric diagnosis of black patients. American Journal of Psychiatry, 138, 279-285.

Akbar, N. (1980). Mental disorders among African Americans, Black Caucus Journal, 11, 1-7.

Bell, C.C., Mehta, H. (1980). The misdiagnosis of black patients with manic depressive illness. Journal of the National Medical Association, 72, 141-145.

Bell, C.C., Mehta, H. (1981). Misdiagnosis of black patients with manic depressive illness: Second in a series. Journal of the National Medical Association, 73, 101-107.

Casas, M. (1986). Making effective use of research to impact the training of culturally sensitive mental health workers. In M. Miranda, H. Kitano (Eds.), Mental health research and practice in minority communities. Washington, DC: National Institute of Mental Health, DHHS Publication No. (ADM) 86-1466.

Craig, T., Goodman, A., Haugland, G. (1982). Impact of DSM-III on clinical practice. American Journal of Psychiatry, 139, 922-925. 
DeHoyos, A., DeHoyos, G. (1965). Symptomatology differentials between Negro and white schizophrenics. International Journal of Psychiatry, 11, 245-265.

Dohrenwend, B.P., Dohrenwend, B.S. (1974). Social and cultural influences on psychopathology. Annual Review of Psychology, 25, 417-452.

Feighner, J., Herbstein, J., (1987). Diagnostic validity, in C. Last, M. Hershen (Eds.) Issues in diagnostic research. New York: Plenum Press, pp. 121-140.

Figelman, M. (1968). A comparison of affective and paranoid disorders in Negroes and Jews. International Journal of Psychiatry, 14, 277-281.

Fischer, J. (1969). Negroes and whites and rates of mental illness: Reconsideration of a myth. Psychiatry, 32, 428-446.

Frances, A., Shear, K., Fyer, M. (1987). Differential therapeutics: Clinical, teaching, research and administrative issues. In American Psychiatric Association Annual Review, Volume 6. Washington, DC: American Psychiatric Association Press.

Good, B.J., Good, M.D.V. (1986). The cultural context of diagnosis and therapy: A view from medical anthropology. In M. Miranda and H. Kitano (Eds.), Mental health research and practice in minority communities. Washington, DC: National Institute of Mental Health, DHHS Publication No. (ADM) 86-1466.

Gynther, M. Fowler, R., Erdberg, F. (1971). False positives galore: The application of standard MMPI criteria to a rural, isolated, Negro sample. Journal of Clinical Psychology, 27, 234-237.

Hanson, B., Klerman. G. (1974). Interracial problems in the assessment of clinical depression: Concordance differences between black and white psychiatrists and black and white patients. Psychopharmacology Bulletin, 10, 65-66.

Helzer, J.E. (1975). Bipolar affective disorder in black and white men: A comparison of symptoms and familial illness. Archives of General Psychiatry, 32, 1140-143.

Helzer, J., Robins, L., McEvoy, L. et al. (1985). A comparison of clinical and DIS diagnoses: Physician reexamination of lay-interviewed cases in the general population. Archives of General Psychiatry, 42, 657-666.

Hendricks, L., Bayton, J., et al. (1983). NIMH's Diagnostic Interview Schedule: A test of its concurrent validity in a population of black adults. Journal of the National Medical Association, 7, 667-671.

Jones, A.C. (1985). Psychological functioning in black Americans: A conceptual guide for use in psychotherapy. Psychotherapy, 22, 363-369.

Jones, B.E., Gray, B.A., Parson, E.G. (1981). Manic depressive illness among poor urban blacks. American Journal of Psychiatry, 138, 654-657.

Jones, B.E., Robinson, W.M., Parson, E.B., Gray, B.A. (1982). The clinical picture of mania in manic depressive black patients. Journal of the National Medical Association, 74, 553-557.

Jones, B.E., Gray, B.A. (1986). Problems in diagnosing schizophrenia and affective disorders among blacks. Hospital and Community Psychiatry, 37, 61-65.

Kessler, R., Neighbors, H. (1986). A new perspective on the relationships among race, social class and psychological distress. Journal of Health and Social Behavior, 27, 107-115.

Kramer, M., Rosen, B., Willis, E. (1973). Definitions and distributions of mental disorders in a racist society. In C. Willie, M. Kramer, B. Brown (Eds.), Racism and mental health. Pittsburgh: University of Pittsburgh Press.

Lipton, A.A., Simon, F.S. (1985). Psychiatric diagnosis in a state hospital: Manhattan State revisited. Hospital and Community Psychiatry, 36, 368-373.

Liss, J.L., Welner, A., Robins, E., Richardson, M. (1973). Psychiatric symptoms in white and black inpatients I: Record study. Comprehensive Psychiatry, 14, 475-481.

Loring, M., Powell, B. (1988). Gender, race, and DSM-III: A study of the objectivity of psychiatric diagnostic behavior. Journal of Health and Social Behavior, 29, 1-22.

Mukherjee, S., Shukla, S., Woodle, J., Rosen, A.M., Olarte, S. (1983). Misdiagnosis of schizophrenia in bipolar patients: A multiethnic comparison. American Journal of Psychiatry, 140, 1571-1574.

Neighbors, H.W. (1987). Improving the mental health of black Americans: Lessons from the Community Mental Health Movement. The Milbank Quarterly, 65(2), 348-380.

Perry, S. (1987). The choice of duration and frequency for outpatient psychotherapy. In American Psychiatric Association Annual Review, Volume 6. Washington, DC: American Psychiatric Press. 
Prange, A., Vitols, M. (1962). Cultural aspects of relatively low incidence of depression in Southern Negroes. International Journal of Psychiatry, 8, 104-112.

Raskin, A., Crook, T.H., Herman, K.D. (1975). Psychiatric history and symptom differences in black and white depressed inpatients. Journal of Consulting and Clinical Psychology, 43, 73-80.

Roberts, R. (1987). Depression among black and Hispanic Americans. Paper presented at the NIMH Workshop on Depression and Suicide in Minorities, Bethesda, Maryland, December 7-8.

Ruiz, D.S. (1983). Epidemiology of schizophrenia: Some diagnostic and sociocultural considerations. Phylon, 43, 315-326.

Simon, R.J. Fleiss, J.L., Gurland, B.J., Stiller, P.R., Sharpe, L. (1973). Depression and schizophrenia in hospitalized black and white mental patients. Archives of General Psychiatry, 28, 509-512.

Singer, B. (1977). Racial factors in psychiatric intervention. San Francisco: R.E. Research Associates.

Sletten, I., Schuff, S., Altman, H., Ulett, G. (1972). A statewide computerized psychiatric system: Demographic, diagnostic and mental status data. British Journal of Social Psychiatry, 18, $30-40$.

Steinberg, M.D., Pardes, H., Bjork, D., Sporty, L. (1977). Demographic and clinical characteristics of black psychiatric patients in a private general hospital. Hospital and Community Psychiatry, 28, 128-132.

Thomas, A., Sillen, S. (1972). Racism and psychiatry. New York: Bruner/Mazel.

Tonks, C.M., Paykel, E.S., Klerman, G.L. (1970). Clinical depressions among Negroes. American. Journal of Psychiatry, 127, 329-335.

Vernon, S., and Roberts, R. (1981). Measuring nonspecific psychological distress and other dimensions of psychopathology: Further observations on the problem. Archives of General Psychiatry, 38, 1239-1247.

Vitols, M.M., Waters, H.G., Keeler, M.H. (1963). Hallucinations and delusions in white and Negro schizophrenics. American Journal of Psychiatry, 120, 472-476.

Weissman, M., Klerman, G. (1978). Epidemiology of mental disorders: Emerging trends in the United States. Archives of General Psychiatry, 35, 705-712.

WeIner, A., Liss, J.L., Robins, E. (1973). Psychiatric symptoms in white and black inpatients, II: Follow-up study. Comprehensive Psychiatry, 14, 483-488.

Williams, D.H. (1986). The epidemiology of mental illness in Afro-Americans. Hospital and Community Psychiatry, 37, 42-49.

Warheit, G., Holzer, C., Arey, S. (1975). Race and mental illness: An epidemiologic update. Journal of Health and Social Behavior, 16, 243-256. 